Review

\title{
From gantry-based machine to robot-based fused deposition modelling: A state-of-the-art
}

\author{
Mohamed Habibi' ${ }^{1 *}$, Marwa Ziadia ${ }^{1}$ \\ 1 Department of mechanical engineering, University of Quebec at Trois-Rivieres, Quebec, Canada. Mo- \\ hamed.Habibi@uqtr.ca; \\ 1 Department of mechanical engineering University of Quebec at Trois-Rivieres, Quebec, Canada. \\ Marwa.Ziadia@uqtr.ca; \\ * Correspondence: Mohamed.Habibi@uqtr.ca;
}

\begin{abstract}
Over the last decade, significant literature has emerged that advocates the potential of different Additive manufacturing (AM) technologies and printable polymeric materials. Nevertheless, a large-scale printing and complex geometric shapes, with curvatures and non-planar layer deposition, are challenging for the traditional gantry-based machine. The 3 degrees of freedom cartesian configuration restricted their capability to planar layered printing and restricted part dimensions. To date, many researchers have used industrial robots to overcomes this limitation. This review gives the reader a good overview of the FDM technique due to its scalability, cost efficiency and a wide range of material printability. A strong emphasis is laid on the PLA and PLA-based composites as promising materials for the FDM process applications. The second part of this paper links the successful use of these materials in the traditional printing process to large-scale printing using the robot-based FDM process. This survey presents representative setups for robot-based AM and works that have been used these setups for non-planar material deposition. Finally, we conclude this paper by identifying opportunities for realizing new functional capabilities by exploiting robot-based AM, and we also present the future trends in this area.
\end{abstract}

Keywords: Additive manufacturing; Fused Deposition Modelling; Robot-based additive manufacturing; Polylactic acid (PLA) and PLA-based composite.

\section{Introduction}

Additive manufacturing (AM), or more commonly known as 3D printing, differs from subtractive manufacturing processes (Abdulhameed, Al-Ahmari, Ameen, \& Mian, 2019). The final products are usually built by materials deposition in a layer-by-layer process without any conventional tool (Carlier et al., 2019). AM makes it possible to build complex objects in one single process step, eliminating production steps and accelerating time to market with marginally increasing production costs. Whether it consists of Stereolithography (SLA) using photopolymer liquids (Manapat, Chen, Ye, \& Advincula, 2017; Manapat, Mangadlao, Tiu, Tritchler, \& Advincula, 2017; Wang, Martin, Hini, Mills, \& Kim, 2017), Selective Laser Sintering (SLS) using polymer powders (Shirazi, Gharehkhani, Mehrali, Yarmand, Metselaar, Adib Kadri, et al., 2015; Shirazi, Gharehkhani, Mehrali, Yarmand, Metselaar, Kadri, et al., 2015), or Fused Deposition Modelling (FDM) using polymer filaments (Daminabo, Goel, Grammatikos, Nezhad, \& Thakur, 2020; Mohan, Senthil, Vinodh, \& Jayanth, 2017), AM enables rapid fabrication of physical products directly from three-dimensional (3D) data of a computer-aided design (CAD) file (Dickson, Barry, McDonnell, \& Dowling, 2017; Shirazi, Gharehkhani, Mehrali, Yarmand, Metselaar, Adib Kadri, et al., 2015; Valino et al., 2019).

Fused Deposition Modelling (FDM) is the most commonly used 3D printing technique (Ning, Cong, Wei, Wang, \& Zhang, 2015). FDM consists of melting the thermoplastic polymer's filaments through a hot nozzle followed by cooling and solidification to 
construct the final structure in a layer-by-layer process (Afrose, Masood, Iovenitti, Nikzad, \& Sbarski, 2016; Qattawi \& Ablat, 2017). Due to their low cost and low melting temperatures, Polylactic acid (PLA), Acrylonitrile butadiene styrene (ABS), Polyethylene terephthalate (PETG), thermoplastic polyurethane (TPU) and Polycarbonate (PC) are the most utilized polymers (Carlier et al., 2019; Dickson et al., 2017; Sezer \& Eren, 2019; P. Zhao, Rao, Gu, Sharmin, \& Fu, 2018). However, their low mechanical strength is usually the major drawback restricting their use in functional and load-bearing parts printing. Besides, owing to the layer by layer manufacturing, FDM printed parts may suffer from inner porous and weak surface finish, which leads to anisotropic mechanical properties (Ahn, Montero, Odell, Roundy, \& Wright, 2002; Chen, He, Yang, Niu, \& Ren, 2017; Zareiyan \& Khoshnevis, 2017).

Additive manufacturing has successfully left prototyping steps to be used in various applications (Urhal, Weightman, Diver, \& Bartolo, 2019). However, the limited construction platform dimensions and the three-axis Cartesian coordinate-based machines limit applications to small build volume that the process permits (Easter, Turman, Sheffler, Balazs, \& Rotner, 2013; Huang, 2013). Consequently, the limited building volume mitigates the primary benefit of single-step part printing. It might force portioning the design into smaller parts, which adds further assembly steps to the manufacturing process, particularly in large part applications like those for aerospace (Vashishtha, Makade, \& Mehla, 2011), automotive (Bourell, Stucker, Ilardo, \& Williams, 2010) and construction (Qattawi \& Ablat, 2017; Zou et al., 2016).

Several attempts have been made to overcome these limitations that hampered the broader adoption of FDM printing. Multi-axis robots (MARs), usually used for welding and pick-and-place tasks, are emerging as an alternative to extending the dimensional boundaries of the three-axis cartesian coordinate robots (Urhal et al., 2019). Coupling a six-degree-of-freedom (6-DOF) robot with an extruder head for FDM printing improves the final part dimensions and the geometric complexity for extensive multi-scale applications.

The paper is comprised of three sections. Section 1 presents the fused deposition modelling (FDM) process, as the most frequently used in additive manufacturing, and discusses the most commonly used polymers in the FDM-printed parts. Section 2 summarizes the literature review of the development status and the application of PLA polymers and PLA-based composites in FDM. In the third section, the robot-based FDM is emphasized and the corresponding research work using these materials. Finally, the paper ends with a discussion and conclusion on the robot-based AM and its future development trend.

\section{FDM using three-axis Cartesian coordinate machine}

Fused Deposition Modelling (FDM) is one of the most frequently used printing methods in 3D printing of polymers and composites (Yao, Deng, Zhang, \& Li, 2019). As a common concept of all AM methods (Figure 1), the FDM printed part is in the first step prepared as a 3D model using CAD modelling software, such as Auto Cad Solidworks, Catia, Creo etc. Most of the FDM printing setups use the 3D model in .STL file format where a slicing software converts it into the appropriate file type and parameters (G-code), by which the tool path plan is generated to control the machine hardware (Singh, Kumar, \& Singh Chohan, 2020; Valino et al., 2019; Zou et al., 2016). 

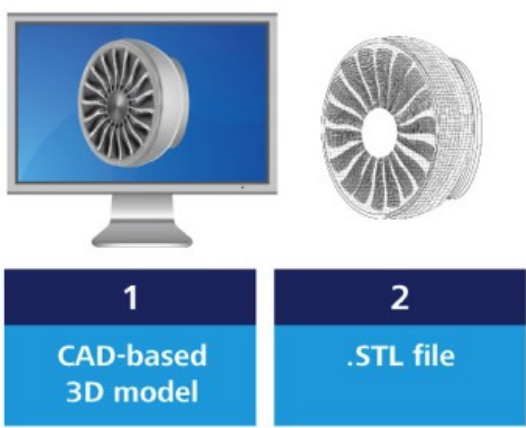

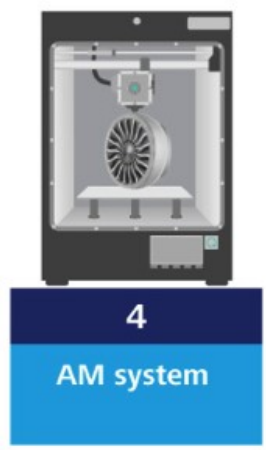

Figure 1. FDM process flow.

The printed part volume results from the up-or-down movements of a nozzle of an extruder head or a printing plate (Figure 2). Depending on the printing setup, the part's volume is mainly built by a movement of the nozzle and/or the printing plate in XYZ directions. Besides, the printing quality, such as surface finish and precision, depends on the printing parameters. The standard settings of different printing machines are the layer thickness, infill density, raster orientation, build orientation, printing temperature, and speed. These parameters should be tuned based on the printed polymer's flow properties (Kaveh, Badrossamay, Foroozmehr, \& Etefagh, 2015).

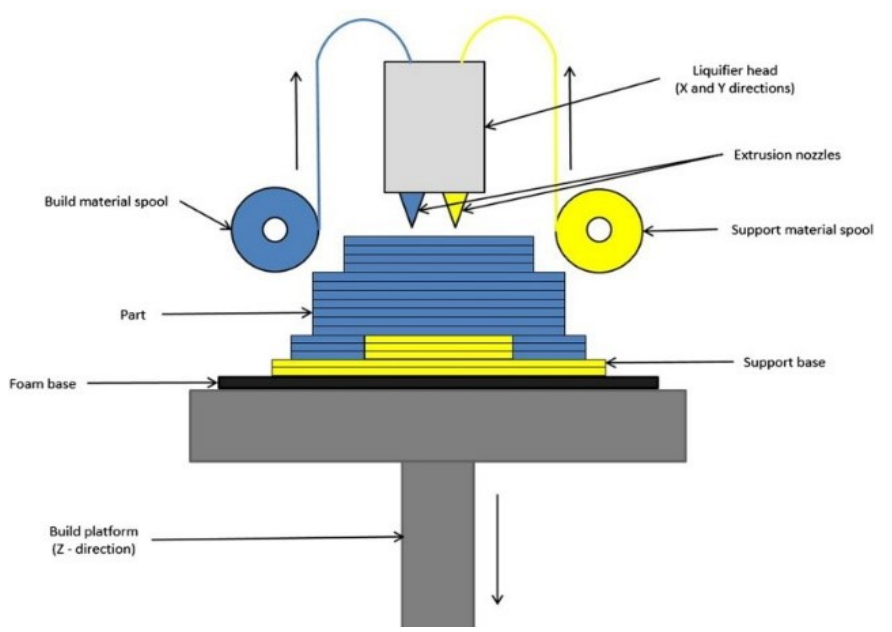

Figure 2. Example of FDM printing setup (Source: (Mohan et al., 2017)).

The printed part increases in height by continuous feeding of quasi-liquid state thermoplastic polymers through at least one liquefier nozzles. The melted polymer cools down during the layer by layer deposition due to the lower surrounding temperature, hardens, and consolidates with the neighbouring layer. Support materials, deposited onto the printing plate to form a foundation for the part, can also be loaded to a secondary nozzle. The support materials are dissolved in a water-based cleaning solution after the printing is completed (Figure 3) (Dikshit, Goh, Nagalingam, Goh, \& Yeong, 2020). 


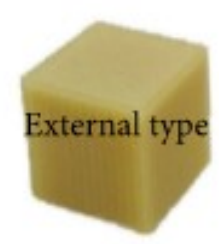

Time (hour): 0

Weight (g): 6.8

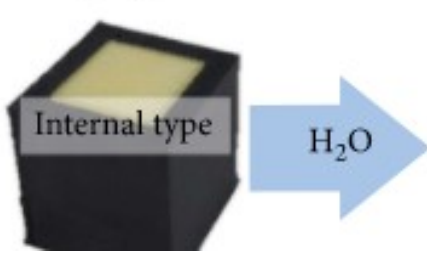

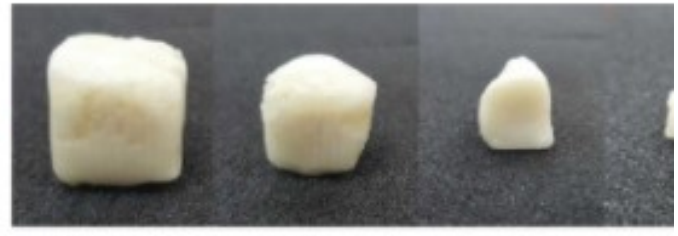

$T: 0.5$

$W: 4.83$

$T: 1$

$W: 3.41$

$T: 1.5$

$W: 2.10$
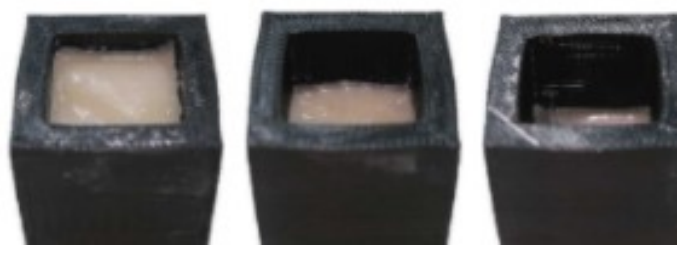

Figure 3. Dissolution of PVA supports in hydrogen peroxide (Source: (Park et al., 2018)).

\section{Thermoplastics polymers for FDM}

For FDM printing, thermoplastic polymers are generally extruded and spooled in a filament of two standard sizes, 1.75 and $3.0 \mathrm{~mm}$ in diameter (Rahim, Abdullah, \& Md Akil, 2019). The most commonly used thermoplastic polymers are shown in Table 1 . The polymers' melting temperature is a crucial parameter to define the process parameters that lead to improved part quality/properties. One of the most critical parameters related to the polymer melting temperature is the temperature of the nozzle. Low melting will lead to inconsistent layer-to-adjacent and layer-to-layer bonding. However, overheating beyond proper melting temperature leads to reduced viscosity and a lengthier time to solidify. Additionally, printing velocity and nozzle temperature should be set considering the melting temperature, where higher speed leads to reduced residence time in the nozzle and a shorter time for heating (Liu et al., 2019).

Table 1. Common thermoplastic polymers for FDM printing (Liu et al., 2019).

\begin{tabular}{cccccc}
\hline Polymer & Melt temp $\left({ }^{\circ} \mathrm{C}\right)$ & Strength & Flexibility & Durability & Shrinkage \\
\hline PLA & $\approx 200$ & High & Low & Medium & Low \\
& Comment: Easy to print and nonsoluble with the support materials dissolving solution \\
\hline ABS & $\approx 230$ & High & Medium & High & Significant \\
& \multicolumn{4}{c}{ Comment: } & Relatively finicky and sensitive to esters and acetone \\
\hline PETG & $\approx 230$ & High & Medium & High & Low \\
\multicolumn{4}{c}{ Comment: Most commonly used in FDM and nonsoluble } \\
\hline TPU & $\approx 250$ & High & High & High & Significant \\
& Comment: commonly used for functional prototypes, relatively finicky and nonsoluble \\
\hline PC & $\approx 300$ & Very high & Medium & Very high & Significant \\
& Comment: relatively finicky, Strongest of the common polymers and nonsoluble \\
\hline
\end{tabular}

In the cases of amorphous polymers such as ABS, there is no crystallization. Thus, the shrinkage due to cooling the polymer from the melting to the ambient temperature is typically significant. Moreover, due to the higher melting and printing temperatures, amorphous polymers printed parts may suffer dimensional precision and an eventual warpage event (Liu et al., 2019).

Depending on their molecular structure and the applied cooling rate, some semi-crystalline polymers have a low degree of crystallinity, typically between 15 and 
80\% (Ehrenstein, 2012; Sender et al., 2007). This behaviour allows using some polyamides polymers in FDM printing due to their lower degree of crystallinity, between 20 and 32\% (Athreya, Kalaitzidou, \& Das, 2011). Polyamide molecules have a high tendency to be cooled in a relatively short time, which is crucial to achieving a successful print with successive additions of thin layers. However, many semi-crystalline polymers, such as polyurethane (TPU), have a high degree of crystallinity. This behaviour makes them less attractive in FDM because of the high degree of shrinkage (Carneiro, Silva, \& Gomes, 2015). During the printing process, a high degree of crystallinity will lead to a fast cooling of the circumferential volume than the rest of the part. Thus, the increase of shrinkage will cause the piece to pull up from the platform.

Also, a high degree of crystallinity can provoke the printed part's warping, mainly in the sharp corners and due to high shrinkage. Even though warping is located at corners and the printed part is still attached to the platform, the printing's uneven surface will prevent flowing at an equal thickness, which causes clogging of the polymers in the nozzle. Besides, polymer clogging will cause the melt flow's local failure, increase the porosity, and reduce the part's mechanical properties (Rahim et al., 2019).

\subsection{Polylactic acid (PLA) polymer}

The growing interest in 3D printing for industrial-level use, the increasing awareness of the environmental impact of polymers and fibre-reinforced polymers and the limited range of biomaterials increase the attractiveness of PLA for its use in FDM applications (Habibi, Laperrière, \& Mahi Hassanabadi, 2019; Habibi, Selmi, Laperrière, Mahi, \& Kelouwani, 2019; Yeong, Chua, Leong, \& Chandrasekaran, 2004). The low glass transition temperature and melting temperature, lower coefficient of thermal expansion, and non-adherence to the printing surface make it a promising thermoplastic for printing purposes (Cuiffo et al., 2017). However, low thermal stability, high degradation rate during processing, low toughness, and moisture sensitivity limit its application (Jo, Kwon, \& Moon, 2018). PLA can be found in semi-crystalline or amorphous grades. Pure poly (l-lactic acid) (PLLA) or poly(D-lactic acid) is semi-crystalline, whereas PLA with 50-93\% L-lactic acid is amorphous. Amorphous PLA exhibits better processability but poor mechanical properties as compared to crystalline.

Several studies have already paid attention to PLA and PLA-based composites because they are critical for industrial and general use. However, the high complexity of setting optimal printing parameters, which highly depend on the polymers properties and their interaction with the printer setup and environment, is one of the major factors that hinder further growth of the PLA usage in FDM. PLA polymers are affected by processing methods. Their influence on mechanical, thermal and rheological properties results in poor mechanical properties of the FDM printed parts compared to those processed by injection moulding (Garlotta, 2001; Rahim et al., 2019).

As mentioned above, the success of polymers in FDM printing depends on the printed part's quality and strength. Polymers extrusion temperature, printing orientation, layer thickness, combined with other printing settings such as print speed and building platform temperature, drastically escalate the number of experiments needed to produce guidelines for the optimal mechanical performance of FDM printed parts.

Valerga et al. (Valerga, Batista, Salguero, \& Girot, 2018) investigated the relationship between the printing parameters and PLA polymer conditions. The manufactured parts result in dimensional terms, surface quality, and mechanical strength. The obtained results clearly showed that the relative humidity was the most relevant variable, where the stored PLA in an atmosphere with low relative humidity has resisted higher tensile forces. Also, polymer melting temperatures have caused water boiling, which is transformed into bubbles, leading to cracks in the mechanical tests. Jo et al. (Jo et al., 2018) showed that the mechanical properties of PLA printed parts are highly correlated to the 
layer thickness. However, externally applied heat and pressure have increased the PLA parts performance due to the bond between raster to raster and layer to layer.

Regarding the effect of nozzle diameter, liquefier temperature, extrusion velocity, filling velocity, and layer thickness of PLA printed parts, Yang et al. (Yang, Li, Li, Yang, \& Yuan, 2019) concluded that the nozzle diameter and layer thickness are the most influencing factors on tensile strength, surface roughness, and build time of printed parts. Other authors such as Alafaghani et al. (Qattawi, Alrawi, \& Guzman, 2017), which studied the effect of process parameters (such as building direction, printing speed, extrusion temperature, layer height) on the mechanical properties of FDM printed PLA parts, concluded that building direction, extrusion temperature, and layer height were more influencing parameters.

Afrose et al. (Afrose et al., 2016) have concluded on the effect of build orientation on the static and cyclic behaviour of PLA printed specimens. Mechanical testing of samples in three $\left(\mathrm{X}, \mathrm{Y}\right.$ and $\left.45^{\circ}\right)$ different build orientations have shown that parts in $\mathrm{X}$ build orientation exhibit higher tensile stress, in the range of $60-64 \%$ of that of injection moulded PLA material, compared to that built-in $\mathrm{Y}$ and $45^{\circ}$ orientations. However, under tensile cyclic loading, $45^{\circ}$ build orientation showed higher fatigue life.

According to Maidin et al. (Maidin, Muhamad, \& Pei, 2015), the joint line where excess material residues in the interface of FDM printed PLA parts induced a negative effect on the mechanical properties and shape precision. They have shown that applying ultrasonic vibration improved the surface finish. The obtained results using different ultrasonic vibration frequencies also approved a possible elimination of manual post-processing at $21 \mathrm{kHz}$.

Zhao et al. (P. Zhao et al., 2018) investigated the potential of closed-loop recycling of PLA used in 3D printing. The result of viscosity measurements showed a significant deterioration of PLA due to the repeated FDM printing cycles. Also, FTIR spectra and SEM micrographs have confirmed that the repeated melt processing caused the degradation of PLA. However, blending recycled PLA with virgin material improved the viscosity, which facilitates the closed-loop recycling process.

Despite the several efforts of the research community in controlling and optimizing FDM key process parameters, the intrinsic mechanical behaviour of pure PLA still the bottlenecks that restrict the further development of 3D printing technology. Several attempts have already been made the PLA modification, which involves improving mechanical properties by 3D extrusion of its composite materials.

\subsection{PLA-based composites}

Although not well-established concepts, FDM printing of reinforced PLA, by addition of particle, filler, fibre or nanomaterial, can well-increase the strength of 3D parts.

The latter compounding PLA with graphene and carbon nanotubes has enhanced the mechanical behaviour of FDM printed parts. Ivanov et al. (Ivanov et al., 2019) investigated the experimental behaviour of PLA reinforced with graphene nanoplates (GNP) and multi-walled carbon nanotubes (MWCNT) with 0-6 wt.\% filler content. The obtained results have shown that the load-bearing for the graphene or MWCNTs kept increasing as a continuous and denser network was formed in the polymer matrix. GNP nano-composites thermal conductivity and diffusivity were improved by adding graphene nanoplatelets by $181 \%$ and $214 \%$, respectively. Similarly, Spinelli et al. (Spinelli et al., 2020) have extruded PLA/GNP, PLA/ MWCNT and PLA/GNP/MWCNT with 0-6 wt.\% filler content. Such filaments in FDM printing have shown $50-150 \%$ higher values of tensile properties. The trend of enhancing the mechanical properties of PLA using GNP and/or MWCNT was confirmed by other researchers such as Kashi et al. (Kashi, Gupta, Kao, Hadigheh, \& Bhattacharya, 2018), Spinelli et al. (Spinelli et al., 2019), Camargo et al. (Camargo, Machado, Almeida, \& Silva, 2019), Prashantha et al. (Prashantha \& Roger, 2017), etc. However, it should be pointed out that the poor adhesion of 
MWCNT with PLA due to the lower active functional groups and low surface energy has a significant effect on the polymer reinforcing. Thus MWCNT must be functionalized using surface treatments to promote the bonding reaction with PLA (Liu et al., 2019).

Fibre-reinforced polymers (FRP) have gained particular attention in the field of composites materials, where they have shown a significant contribution to enhancing mechanical performance (Habibi, Laperrière, Lebrun, \& Toubal, 2017; Habibi, Laperrière, \& Mahi Hassanabadi, 2020; Habibi, Lebrun, \& Laperrière, 2017; Selmi, Habibi, Laperrière, \& Kelouwani, 2020). Thus, fibre-reinforced thermoplastic (FRTP) composites can be useful in FDM printed parts to achieve high load-bearing capability (N. Li, Li, \& Liu, 2016).

Li et al. (N. Li et al., 2016) have reinforced PLA with continuous carbon fibre (CFRPLA) for FDM printing, using a nozzle designed to print continuous fibre, as shown in Figure 4. A preprocessing of carbon fibres was realized using a methylene dichloride solution containing $8 \%$ of partially dissolved PLA particles to improve the interfacial strength between fibre and polymer. The results indicated that modified carbon fibre's tensile strength and flexural strengths were $13.8 \%$ and $164 \%$ higher than the original carbon fibre reinforced PLA. The modified carbon fibre reinforced samples' storage modulus was also higher than the PLA and original fibre reinforced samples for about $166 \%$ and $351 \%$, respectively.

Using the same type of filament (CFRPLA), Tian et al. (Tian et al., 2017; Tian, Liu, Yang, Wang, \& Li, 2016) studied the process parameters' influence on interfaces and performance of printed composite parts. They have successfully established the correlations between the process parameters and part performance. The better bonding strength between lines and layers was obtained with a layer thickness from $0.4 \mathrm{~mm}$ to $0.6 \mathrm{~mm}$ and a hatch spacing of around $0.6 \mathrm{~mm}$. Also, the obtained results have shown that optimal printing parameters at the fibre content of $27 \%$ allow achieving a flexural strength of 335 $\mathrm{MPa}$ and modulus of $30 \mathrm{GPa}$.

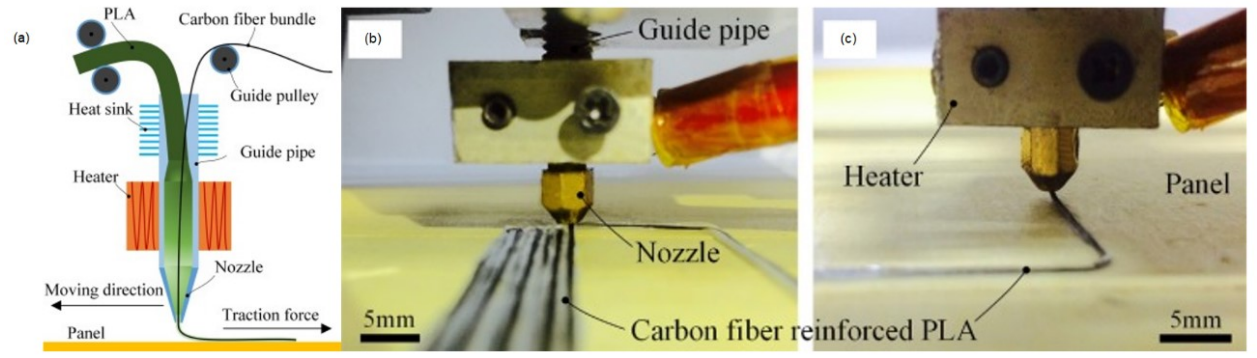

Figure 4. (a) Schematic of the extrusion device and (b) straight area and (c) corner printing of continuous carbon fibre reinforced PLA (Source: (N. Li et al., 2016)).

As is shown in Figure 4, Matsuzaki et al. (N. Li et al., 2016) have developed a method for FDM printing of CFRPLA and twisted yarns of jute fibres reinforced PLA (JFRPLA). The tensile strength of the printed composites has shown a significant increase when compared to pure PLA filament. For CFRPLA, tensile modulus and strength are $19.5 \mathrm{GPa}$ and $185.2 \mathrm{MPa}$, respectively, 599\% and 435\% higher than pure PLA. For JFRPLA, the tensile modulus and strength are $5.11 \mathrm{GPa}$ and $57.1 \mathrm{MPa}$, corresponding to $157 \%$ and $134 \%$ of those shown by the PLA, respectively.

Ferreira et al. (Ferreira, Amatte, Dutra, \& Bürger, 2017) experimented with PLA filament reinforced with short carbon fibres (SCFRPLA) in a weight fraction of $15 \%$ (Figure 5). They have found that the reinforced material has two times higher tensile modulus in the printing direction. The same trend was confirmed by Ivey et al. (Ivey, 
Melenka, Carey, \& Ayranci, 2017), where the elastic modulus of pure PLA parts was increased from 3.51 GPa to 6.26 GPa by adding short carbon fibres.

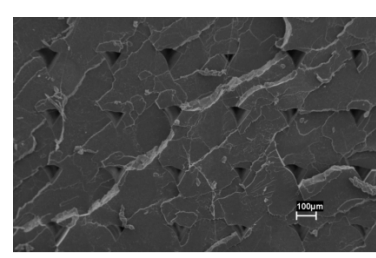

Specimen of PLA at $0^{\circ}$ magnified $\times 200$

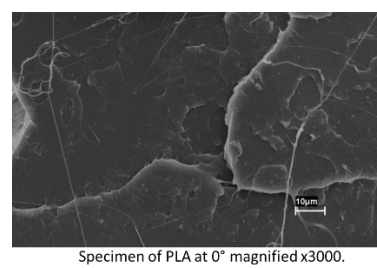

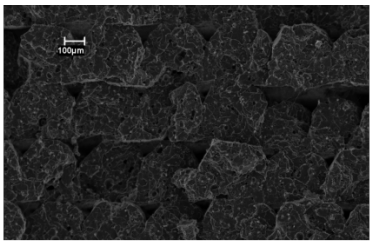

Specimen of PLA+CF at $0^{\circ}$ magnified $\times 200$

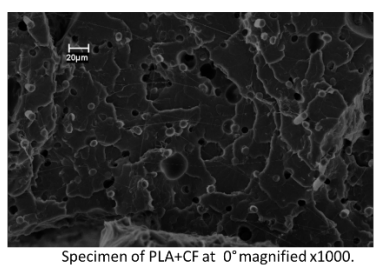

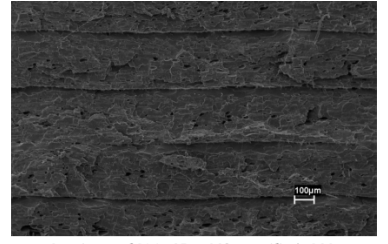

Specimen of PLA+CF at $90^{\circ}$ magnified $\times 200$

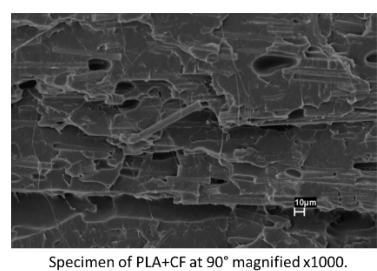

Figure 5. The fracture surface of PLA and PLA+CF specimen printed at $0^{\circ}$ and $90^{\circ}$ (Source: (Ferreira et al., 2017)).

Murphy et al. (Murphy \& Collins, 2018) have reinforced PLA with microcrystalline cellulose (MCC) at different weight ratios of 1, 3, and $5 \mathrm{wt} \%$. Cellulose surface was modified using a titanate coupling agent to improve the surface adherence. Dynamic mechanical thermal analysis results have shown an increase of the storage modulus, with the most significant improvement at $3 \mathrm{wt} \%$ of modified cellulose.

Filgueira et al. (Filgueira et al., 2017) have used an enzymatic modification via laccase-assisted grafting of octyl gallate (OG), or lauryl gallate (LG) of thermomechanical pulp (TMP) fibres in the PLA reinforced filaments development for FDM printing. Although all manufactured filaments were printable, OG-treated surfaces have allowed better stress transfer from PLA to the fibres during mechanical testing.

A 5 wt \% wood flour (WF) reinforced PLA (WFRPLA) filament was developed by Tao et al. (Tao, Wang, Li, Li, \& Shi, 2017) for biocomposites printed part. The obtained results from the experimental investigation, using tensile properties, microstructure, thermogravimetric analysis (TGA), differential scanning calorimetry (DSC) and X-ray diffraction (XRD), have clearly shown an enhanced deformation resistance of the composite after adding WF. Also, the starting thermal degradation temperature of the composites decreased slightly. However, the final thermal decomposition residual ratio of the composites increased with no effects on the melting temperature of the PLA $5 \mathrm{wt} \%$.

\section{Robot-based FDM}

Inspired from conventional 3-axes FDM printers, the multi-axis Additive Robot Manufacturing System (ARMS) has been used to achieve dimensional extension, giving designers more design freedom and an extension of the printed part dimensions to meet the industrial application requirements. Also, the additional degrees of freedom (DOF) over a conventional gantry-based machine (3-axis CNC machines) can be used for multi-axis printing to accommodate parts larger than the arm itself (Keating \& Oxman, 2013). Additional DOF is useful to reduce production time, as fewer setup changes are required and improved the printed parts' quality (L. Li, Haghighi, \& Yang, 2018). The development of an ARMS is challenging as it requires applying reverse kinematics to program the mechanism's kinematic configurations. However, employing an industrial robot is advantageous, where the link and joint motions are already programmed. There are several commercial multi-axis Computer-Aided Manufacturing (CAM) packages for conventional machining, but there is a lack of such for FDM printing (Isa \& Lazoglu, 2019). However, sequentially FDM printed parts in discrete build orientations can be re- 
alized using conventional slicers. Hence, the 3D model can be partitioned algorithmically and fabricated at different build orientations using a multi-axis arm robot (Lee \& Jee, 2015).

Researchers have focused on different ways of multi-axial additive manufacturing. Some researchers use multi-axis CNC machines to get more than $3 \mathrm{DOF}$, while others focus on robot-based additive manufacturing for greater flexibility. Both approaches have their respective advantages. The higher flexibility and scalability of the robotic systems attenuate the effect of their challenging higher initial investment compared to a multi-axis CNC system (Prahar M. Bhatt, Malhan, Shembekar, Yoon, \& Gupta, 2020). Table 2 summarizes the most recent research work on robot-based additive manufacturing of PLA parts.

Ishak et al. (Ishak, Fisher, \& Larochelle, 2016) integrated an existing FDM extruder with a 6 DOF industrial robot arm to create a 3D printer with a multi-plane layering capability. They have successfully shown that inner and outer toolpaths can be printed in the horizontal plane and vertical planes. Two years later, the same research team developed a three-dimensional lattice structure generator to generate a toolpath for multi-plane FDM printing applications (Ishak IB, 2018). As shown in Figure 6, the geometric input model was printed using a 6 DOF arm platform.
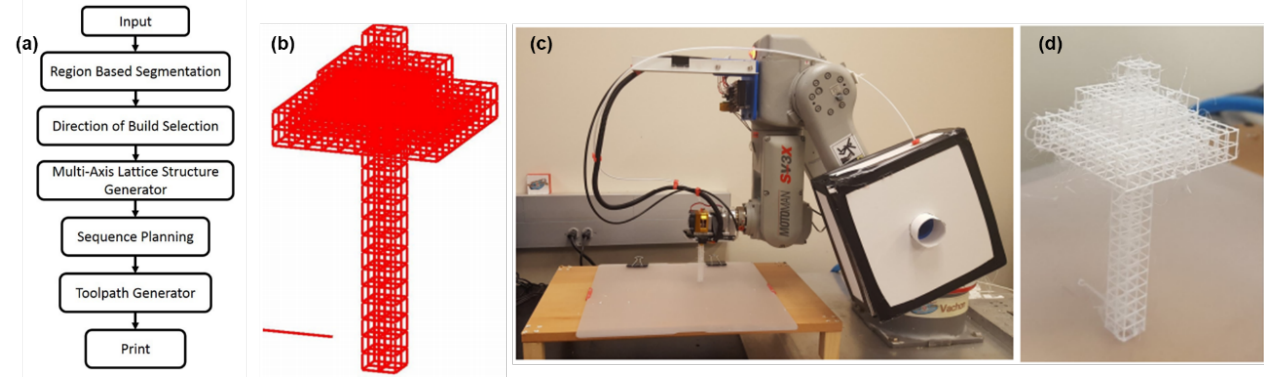

Figure 6. (a) Overview of the algorithm, (b) Simulated toolpath, (c) Robot arm FDM platform and (d) FDM printed 3d lattice (Source: (Ishak IB, 2018))

Bhatt et al. (Prahar M Bhatt, Kabir, et al., 2019) used two 6 DOF ABB arm capable of printing non-planar and/or planar layers and enabling FDM multi-resolution printing. The experimental setup and printing process are shown in Figure 7. The first arm is equipped with a large diameter nozzle to print interior regions of the part at high build rates. The second arm is equipped with a small diameter nozzle to print exterior regions of the part with a smooth surface finish. The combination of two arms reduces the build time of large parts without sacrificing surface finish. Also, the high flexibility in manipulating the print head enables to deposit of materials on a non-planar surface.

Table 2. Robot-based FDM of PLA parts.

\begin{tabular}{cccc}
\hline Reference & Robot and extruder type & DOF & Objective \\
\hline $\begin{array}{c}\text { Alsharhan et al. } \\
\text { (Alsharhan, } \\
\begin{array}{c}\text { Aentea, \& Gupta, } \\
\text { 2017) }\end{array}\end{array}$ & $\begin{array}{c}\text { ABB IRB-120 arm manipu- } \\
\text { lator and a RepRap FDM } \\
\text { extruder (stepper motor, } \\
\text { heater, thermistor) }\end{array}$ & 6 & $\begin{array}{c}\text { Study the effect of planar and } \\
\text { non-planar layer deposition on a } \\
\text { thin-walled model's geometric and } \\
\text { mechanical attributes. }\end{array}$ \\
\hline $\begin{array}{c}\text { Shembekar et al. } \\
\text { Shembekar, Yoon, } \\
\text { Kanyuck, \& Gupta, } \\
\text { 2018) }\end{array}$ & $\begin{array}{c}\text { ABB robot and a cus- } \\
\text { tom-designed fused deposi- } \\
\text { tion modelling (FDM) ex- } \\
\text { truder }\end{array}$ & 6 & $\begin{array}{c}\text { Development of collision-free trajec- } \\
\text { tory planning for robot-based printing } \\
\text { using a non-planar deposition. }\end{array}$ \\
\hline $\begin{array}{c}\text { Ishak et al. (Ishak \& } \\
\text { Larochelle, 2017) }\end{array}$ & $\begin{array}{c}\text { Motoman model SV3X robot } \\
\text { and a 0.4 mm extended noz- }\end{array}$ & 6 & $\begin{array}{c}\text { performing multi-plane toolpath mo- } \\
\text { tions for 3D lattice structure parts }\end{array}$ \\
\hline
\end{tabular}




\begin{tabular}{|c|c|c|c|}
\hline & $\begin{array}{l}\text { zle with air forced cooling } \\
\text { system }\end{array}$ & & printing. \\
\hline $\begin{array}{l}\text { Shembekar et al. } \\
\text { (Shembekar, Yoon, } \\
\text { Kanyuck, \& Gupta, } \\
\text { 2019) }\end{array}$ & $\begin{array}{c}\text { ABB robot and a cus- } \\
\text { tom-designed fused deposi- } \\
\text { tion modelling (FDM) ex- } \\
\text { truder }\end{array}$ & 6 & $\begin{array}{l}\text { Tool path generation for non-planar } \\
\text { Layers }\end{array}$ \\
\hline $\begin{array}{l}\text { Ishak et al. (Bin } \\
\text { Ishak, Fisher, \& } \\
\text { Larochelle, 2016) }\end{array}$ & $\begin{array}{l}\text { Motoman model SV3X robot } \\
\text { and m Reprap J-head ex- } \\
\text { truder }\end{array}$ & 6 & $\begin{array}{l}\text { Development of multi-plane toolpath } \\
\text { motions that will leverage the in- } \\
\text { creased capability of the robot arm } \\
\text { platform compared to conventional } \\
\text { printers }\end{array}$ \\
\hline $\begin{array}{l}\text { Bhatt et al. (Prahar } \\
\text { M Bhatt, Kabir, et } \\
\text { al., 2019) }\end{array}$ & $\begin{array}{c}\text { Two } 6 \text { DOF robot: ABB IRB } \\
120 \text { \& IRB } 2600 \text { and two } \\
\text { FDM extruders with } 0.4 \text { and } \\
0.8 \text { mm nozzles } \\
\end{array}$ & $6+6$ & $\begin{array}{l}\text { Development of multi-resolution lay- } \\
\text { ers and generating collision-free tra- } \\
\text { jectories for robot-based printing. }\end{array}$ \\
\hline $\begin{array}{l}\text { Wulle et al. (Wulle } \\
\text { et al., 2017) }\end{array}$ & Custom five-axis AM setup & 5 & $\begin{array}{l}\text { Optimization of the workpiece proper- } \\
\text { ties by changing the orientation of the } \\
\text { extruded filament based on external } \\
\text { loads and surface quality requirements } \\
\text { and minimization of support material. }\end{array}$ \\
\hline $\begin{array}{l}\text { Wu et al. (Wu, Dai, } \\
\text { Fang, Liu, \& Wang, } \\
\text { 2017) }\end{array}$ & $\begin{array}{l}\text { UR3 robotic arm and FDM } \\
\text { extruder }\end{array}$ & 6 & $\begin{array}{l}\text { Development of a new algorithm for } \\
\text { decomposed models into support-free } \\
\text { parts that can be printed one by one in } \\
\text { a collision-free sequence. }\end{array}$ \\
\hline $\begin{array}{l}\text { Zhao et al. (G. } \\
\text { Zhao, Ma, Feng, \& } \\
\text { Xiao, 2018) }\end{array}$ & $\begin{array}{l}\text { KUKA robot and FDM ex- } \\
\text { truder }\end{array}$ & 6 & $\begin{array}{l}\text { Development of a new decomposi- } \\
\text { tion-based curved surface slicing and } \\
\text { transformation-based cylinder surface } \\
\text { slicing methods for toolpaths genera- } \\
\text { tion. }\end{array}$ \\
\hline $\begin{array}{l}\text { Kutzer et al. } \\
\text { (Kutzer, DeVries, \& } \\
\text { Blas, 2018) }\end{array}$ & $\begin{array}{l}\text { Odense Universal Robot } \\
\text { UR10 and Bondtech QR } \\
\text { 1.75mm Universal Extruder }\end{array}$ & 6 & $\begin{array}{c}\text { Development of a new method for } \\
\text { estimating the 3D internal structure } \\
\text { using image data from a single digital } \\
\text { camera. }\end{array}$ \\
\hline
\end{tabular}

Similarly, Wu et al. used a 6 DOF UR3 robotic arm to provide FDM printed parts from PLA filament, with minimal or no support structures. A nozzle with a $1 \mathrm{~mm}$ hole was used for quick fabrication, and another one of $2 \mathrm{~mm}$ hole was used for enhanced surface quality and more geometric details. A computational tool was developed to decompose the 3D part model into multiple support-free smaller parts using a coarse-to-fine decomposition algorithm, which first segments a model into multiple parts according to the skeleton-based shape analysis. The hardware system allows printing sub-parts, incorporating the collision-free constraint, before applying a fine-level partition to refine the sequence of printing. 

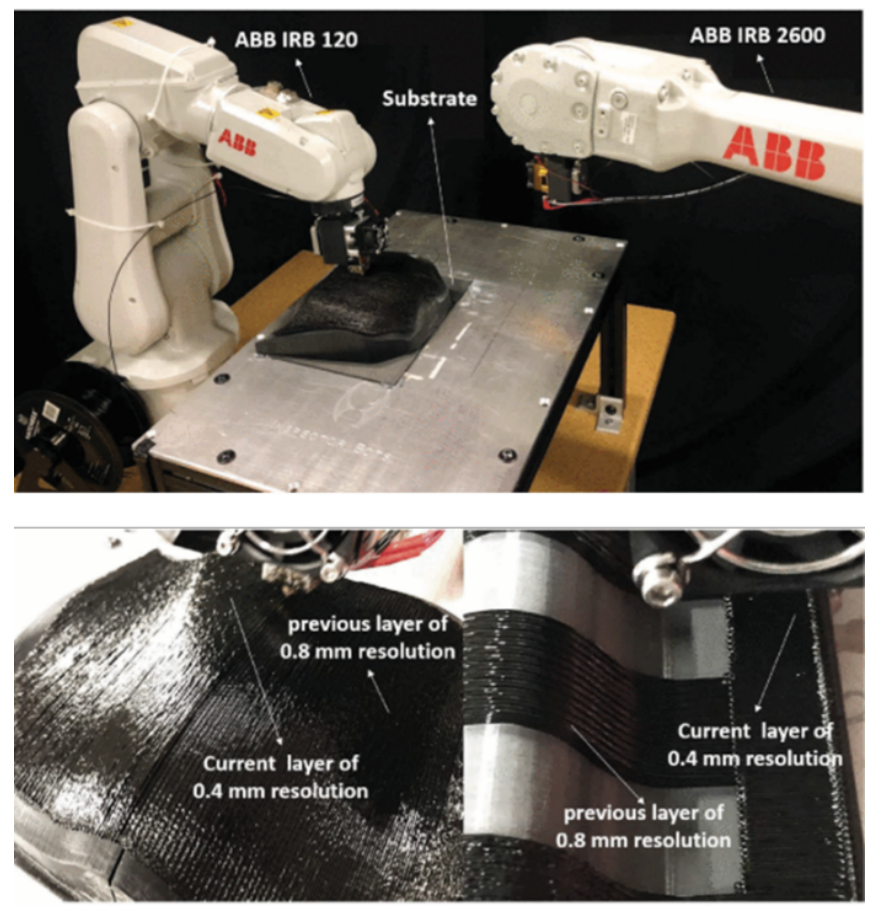

Figure 7. Experimental setup and printing process (Source: (Prahar M Bhatt, Kabir, et al., 2019)).

Zhang et al. (Zhang et al., 2016) used a robotic simulation and offline programming software RobotStudio, an $\mathrm{ABB}$ platform for robotic additive manufacturing process simulation and virtual part representation, to simulate FDM with different printing parameters (Figure 8). They showed that the part building path and bead size could be tuned based on the AM path, FDM equipment, robot model, extrusion head types, configuration, and building temperature and material properties.
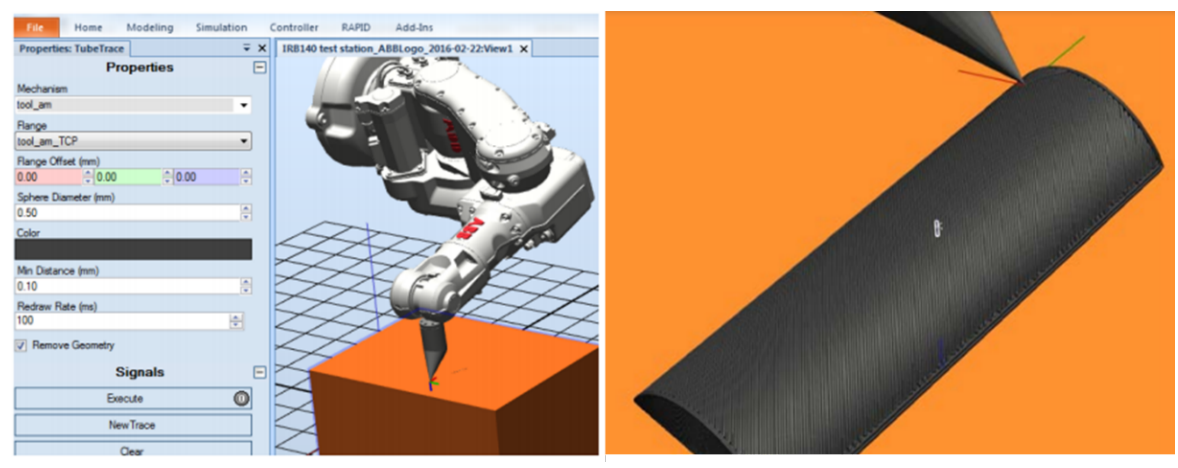

Figure 8. Simulation software and simulated FDM printed part (Source: (Zhang et al., 2016)).

In another work, Fry et al. (Fry NR, 2020) used two Denso VS-068 6-axis robot arms to investigate: the effect of PLA parts printing at different orientations with respect to gravity, the effect of dynamically changing build orientation concerning the build plate when printing overhanging features, and the effect of printing curved parts using curved conformal layers. The first arm robot was designated as Extruder Robot (RE), allowing the nozzle to be positioned relative to the build plate. The second arm robot was designated as Build Plate Robot (RP), moving the printing plate, as shown in Figure 9. 


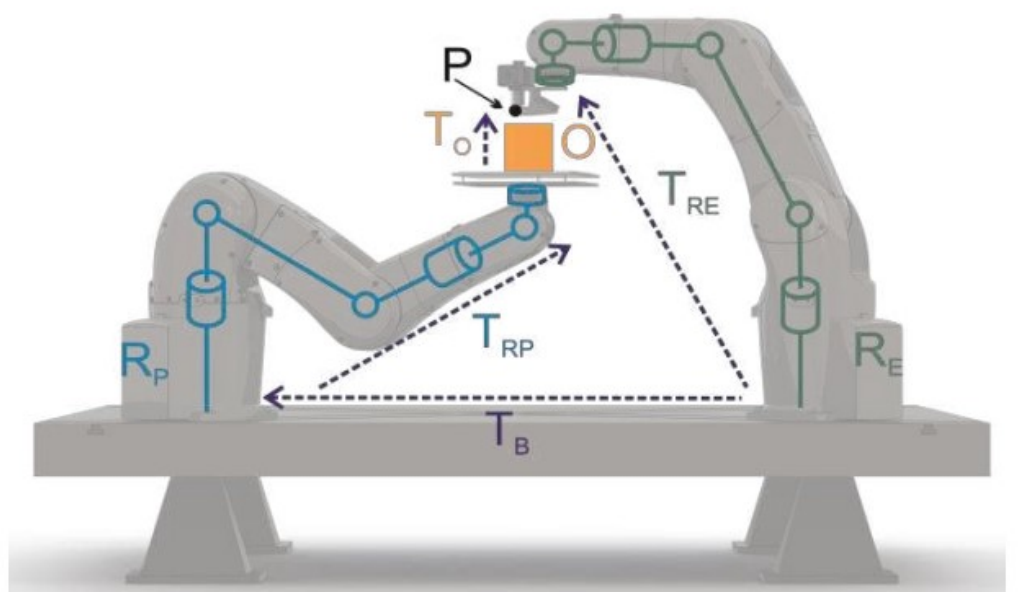

Figure 9. Side view of the system showing the Build Plate (RP), and Extruder (RE) robots and the printed object (O) (Source: (Fry NR, 2020)).

They have proved that the printed part's surface roughness is independent of the print orientation concerning gravity, where the orientation does not affect print quality. Also, dynamically changing build orientation allows overhangs up to $90^{\circ}$ to be cleanly printed without support structures. The use of two arms has allowed concluding that curved layers improve an arch's strength, which is steeply curved and printed with the nozzle remaining normal to the curvature.

\section{Conclusion: Challenges and Opportunities}

Improving the flexibility, productivity and agility of AM techniques are the keys to the competitive manufacturing industry. Gantry-based printing machines have great potential to reduce time to market, increasing product customization and broadening the design options. However, limitations (i.e. limited product size, built rates and the need for a support structure for regions with overhang) drive researchers to develop enhanced additive manufacturing strategies. Non-planar printing processes using 6-DOF articulated robot arms can significantly expand the capabilities of the additive manufacturing processes. As described in this paper, adding an extra DOF to the additive manufacturing process allows changing the direction of material accumulated during the printing process, material deposition on complex non-planar layers and overhang features without printing support structures.

Unlike conventional gantry systems, robotic arms are ideal for creating large parts. They can be placed anywhere, allowing part production in a controlled environment or a combination of multiple techniques (e.g. robotic systems printing different materials and robotic systems performing inspection tasks) (Bandari, Williams, Ding, \& Martina, 2015). Since a single robot can handle various extruding heads or multiple robots can work in the same station, robot-based printing can build multi-material and multi-resolution parts. However, this will require complex motion planning and control where collision-free trajectories need to be generated for the robots under constraints (Prahar M Bhatt, Rajendran, McKay, \& Gupta, 2019). Also, robot-based AM setup must ensure high accuracy where they usually use control systems that can potentially need sophisticated compensation algorithms.

High DOF robot setups can be developed using multi-robot systems, which can work synchronously and asynchronously to print the parts faster using conformal and multi-resolution printing. Although multi-robots can successfully coordinate with each 
other, printing one or multi-part sections will require solving a complex motion planning and control problem. Collision-free trajectories need to be generated for the robots under constraints while the optimum trajectory and process parameters for supportless AM to move the robots efficiently (Prahar M. Bhatt et al., 2020; Urhal et al., 2019). The rapid development of the motion planning algorithm will allow robots to adapt their functions in real-time due to changes in the surrounding environment, where multiple robot-assisted additive manufacturing systems could be used both off-site and on-site. This will also facilitate the development of smart additive manufacturing systems by optimizing the production processes and selecting the most suitable fabrication strategy to produce a part using artificial intelligence (AI).

\section{References}

1. Abdulhameed, O., Al-Ahmari, A., Ameen, W., \& Mian, S. H. (2019). Additive manufacturing: Challenges, trends, and applications. Advances in Mechanical Engineering, 11(2), 1687814018822880.

2. Afrose, M. F., Masood, S., Iovenitti, P., Nikzad, M., \& Sbarski, I. (2016). Effects of part build orientations on fatigue behaviour of FDM-processed PLA material. Progress in Additive Manufacturing, 1(1-2), 21-28.

3. Ahn, S. H., Montero, M., Odell, D., Roundy, S., \& Wright, P. K. (2002). Anisotropic material properties of fused deposition modeling ABS. Rapid prototyping journal.

4. Alsharhan, A. T., Centea, T., \& Gupta, S. K. (2017). Enhancing mechanical properties of thin-walled structures using non-planar extrusion based additive manufacturing. Paper presented at the International Manufacturing Science and Engineering Conference.

5. Athreya, S. R., Kalaitzidou, K., \& Das, S. (2011). Mechanical and microstructural properties of Nylon-12/carbon black composites: Selective laser sintering versus melt compounding and injection molding. Composites science and technology, 71(4), 506-510.

6. Bandari, Y. K., Williams, S. W., Ding, J., \& Martina, F. (2015). Additive manufacture of large structures: Robotic or CNC systems. Paper presented at the Proceedings of the 26th international solid freeform fabrication symposium, Austin, TX, USA.

7. Bhatt, P. M., Kabir, A. M., Malhan, R. K., Shah, B., Shembekar, A. V., Yoon, Y. J., \& Gupta, S. K. (2019). A robotic cell for multi-resolution additive manufacturing. Paper presented at the 2019 International Conference on Robotics and Automation (ICRA).

8. Bhatt, P. M., Malhan, R. K., Shembekar, A. V., Yoon, Y. J., \& Gupta, S. K. (2020). Expanding capabilities of additive manufacturing through use of robotics technologies: A survey. Additive Manufacturing, 31, 100933. doi:https://doi.org/10.1016/j.addma.2019.100933

9. Bhatt, P. M., Rajendran, P., McKay, K., \& Gupta, S. K. (2019). Context-dependent compensation scheme to reduce trajectory execution errors for industrial manipulators. Paper presented at the 2019 International Conference on Robotics and Automation (ICRA).

10. Bin Ishak, I., Fisher, J., \& Larochelle, P. (2016). Robot arm platform for additive manufacturing using multi-plane toolpaths. Paper presented at the International Design Engineering Technical Conferences and Computers and Information in Engineering Conference.

11. Bourell, D., Stucker, B., Ilardo, R., \& Williams, C. B. (2010). Design and manufacture of a Formula SAE intake system using fused deposition modeling and fiber-reinforced composite materials. Rapid prototyping journal.

12. Camargo, J. C., Machado, Á. R., Almeida, E. C., \& Silva, E. F. M. S. (2019). Mechanical properties of PLA-graphene filament for FDM 3D printing. The International Journal of Advanced Manufacturing Technology, 103(5-8), 2423-2443.

13. Carlier, E., Marquette, S., Peerboom, C., Denis, L., Benali, S., Raquez, J. M., . . . Goole, J. (2019). Investigation of the parameters used in fused deposition modeling of poly(lactic acid) to optimize 3D printing sessions. International Journal of Pharmaceutics, 565, 367-377. doi:https://doi.org/10.1016/j.ijpharm.2019.05.008

14. Carneiro, O. S., Silva, A., \& Gomes, R. (2015). Fused deposition modeling with polypropylene. Materials $\mathcal{E}$ Design, 83, 768-776.

15. Chen, L., He, Y., Yang, Y., Niu, S., \& Ren, H. (2017). The research status and development trend of additive manufacturing technology. The International Journal of Advanced Manufacturing Technology, 89(9-12), 3651-3660.

16. Cuiffo, M. A., Snyder, J., Elliott, A. M., Romero, N., Kannan, S., \& Halada, G. P. (2017). Impact of the fused deposition (FDM) printing process on polylactic acid (PLA) chemistry and structure. Applied Sciences, 7(6), 579.

17. Daminabo, S. C., Goel, S., Grammatikos, S. A., Nezhad, H. Y., \& Thakur, V. K. (2020). Fused deposition modeling-based additive manufacturing (3D printing): techniques for polymer material systems. Materials Today Chemistry, 16, 100248. doi:https://doi.org/10.1016/j.mtchem.2020.100248

18. Dickson, A. N., Barry, J. N., McDonnell, K. A., \& Dowling, D. P. (2017). Fabrication of continuous carbon, glass and Kevlar fibre reinforced polymer composites using additive manufacturing. Additive Manufacturing, 16, 146-152. doi:https://doi.org/10.1016/j.addma.2017.06.004

19. Dikshit, V., Goh, G. D., Nagalingam, A. P., Goh, G. L., \& Yeong, W. Y. (2020). Chapter 17 - Recent progress in 3D printing of fiber-reinforced composite and nano-composites. In B. Han, S. Sharma, T. A. Nguyen, L. Longbiao, \& K. S. Bhat (Eds.), Fiber-Reinforced Nano-composites: Fundamentals and Applications (pp. 371-394): Elsevier. 
20. Easter, S., Turman, J., Sheffler, D., Balazs, M., \& Rotner, J. (2013). Using advanced manufacturing to produce unmanned aerial vehicles: a feasibility study. Paper presented at the Ground/Air Multisensor Interoperability, Integration, and Networking for Persistent ISR IV.

21. Ehrenstein, G. W. (2012). Polymeric materials: structure, properties, applications: Carl Hanser Verlag GmbH Co KG.

22. Ferreira, R. T. L., Amatte, I. C., Dutra, T. A., \& Bürger, D. (2017). Experimental characterization and micrography of 3D printed PLA and PLA reinforced with short carbon fibers. Composites Part B: Engineering, 124, 88-100. doi:https://doi.org/10.1016/j.compositesb.2017.05.013

23. Filgueira, D., Holmen, S., Melbø, J. K., Moldes, D., Echtermeyer, A. T., \& Chinga-Carrasco, G. (2017). Enzymatic-assisted modification of thermomechanical pulp fibers to improve the interfacial adhesion with poly (lactic acid) for 3D printing. ACS Sustainable Chemistry \& Engineering, 5(10), 9338-9346.

24. Fry NR, R. R., Boyle JH. (2020). Robotic additive manufacturing system for dynamic build orientations. . Rapid prototyping journal.

25. Garlotta, D. (2001). A literature review of poly (lactic acid). Journal of Polymers and the Environment, 9(2), 63-84.

26. Habibi, M., Laperrière, L., Lebrun, G., \& Toubal, L. (2017). Combining short flax fiber mats and unidirectional flax yarns for composite applications: Effect of short flax fibers on biaxial mechanical properties and damage behaviour. Composites Part B: Engineering, 123, 165-178. doi:https://doi.org/10.1016/j.compositesb.2017.05.023

27. Habibi, M., Laperrière, L., \& Mahi Hassanabadi, H. (2019). Replacing stitching and weaving in natural fiber reinforcement manufacturing, part 1: mechanical behavior of unidirectional flax fiber composites. Journal of Natural Fibers, 16(7), $1064-1076$. doi:10.1080/15440478.2018.1448321

28. Habibi, M., Laperrière, L., \& Mahi Hassanabadi, H. (2020). Replacing stitching and weaving in natural fiber reinforcement manufacturing, part 2: mechanical behavior of flax fiber composite laminates. Journal of Natural Fibers, 17(3), 388-397. doi:10.1080/15440478.2018.1494079

29. Habibi, M., Lebrun, G., \& Laperrière, L. (2017). Experimental characterization of short flax fiber mat composites: tensile and flexural properties and damage analysis using acoustic emission. Journal of Materials Science, 52(11), 6567-6580. doi:10.1007/s10853-017-0892-1

30. Habibi, M., Selmi, S., Laperrière, L., Mahi, H., \& Kelouwani, S. (2019). Experimental investigation on the response of unidirectional flax fiber composites to low-velocity impact with after-impact tensile and compressive strength measurement. Composites Part B: Engineering, 171, 246-253. doi:https://doi.org/10.1016/j.compositesb.2019.05.011

31. Huang, W. (2013). How to treat additive manufacturing (3D printing) from a rational perspective. Advanced Materials Industry, $1(8), 9-12$.

32. Isa, M. A., \& Lazoglu, I. (2019). Five-axis additive manufacturing of freeform models through buildup of transition layers. Journal of Manufacturing Systems, 50, 69-80. doi:https://doi.org/10.1016/j.jmsy.2018.12.002

33. Ishak, I., Fisher, J., \& Larochelle, P. (2016). Robot arm platform for additive manufacturing: Multi-plane printing. Paper presented at the Proceedings of the 2016 Florida Conference on Recent Advances in Robotics (FCRAR 2016).

34. Ishak, I., \& Larochelle, P. (2017). Robot arm platform for additive manufacturing: $3 d$ lattice structures. Paper presented at the 30th Florida Conference on Recent Advances in Robotics.

35. Ishak IB, M. M., Larochelle P. . (2018). An algorithm for generating 3D lattice structures suitable for printing on a multi-plane FDM printing platform. . Paper presented at the International Design Engineering Technical Conferences and Computers and Information in Engineering Conference.

36. Ivanov, E., Kotsilkova, R., Xia, H., Chen, Y., Donato, R. K., Donato, K., . . Cimmino, S. (2019). PLA/Graphene/MWCNT composites with improved electrical and thermal properties suitable for FDM 3D printing applications. Applied Sciences, 9(6), 1209.

37. Ivey, M., Melenka, G. W., Carey, J. P., \& Ayranci, C. (2017). Characterizing short-fiber-reinforced composites produced using additive manufacturing. Advanced Manufacturing: Polymer \& Composites Science, 3(3), 81-91.

38. Jo, W., Kwon, O.-C., \& Moon, M.-W. (2018). Investigation of influence of heat treatment on mechanical strength of FDM printed 3D objects. Rapid prototyping journal.

39. Kashi, S., Gupta, R. K., Kao, N., Hadigheh, S. A., \& Bhattacharya, S. N. (2018). Influence of graphene nanoplatelet incorporation and dispersion state on thermal, mechanical and electrical properties of biodegradable matrices. Journal of materials science $\mathcal{E}$ technology, 34(6), 1026-1034.

40. Kaveh, M., Badrossamay, M., Foroozmehr, E., \& Etefagh, A. H. (2015). Optimization of the printing parameters affecting dimensional accuracy and internal cavity for HIPS material used in fused deposition modeling processes. Journal of materials processing technology, 226, 280-286.

41. Keating, S., \& Oxman, N. (2013). Compound fabrication: A multi-functional robotic platform for digital design and fabrication. Robotics and Computer-Integrated Manufacturing, 29(6), 439-448. doi:https://doi.org/10.1016/j.rcim.2013.05.001

42. Kutzer, M. D., DeVries, L. D., \& Blas, C. D. (2018). Part Monitoring and Quality Assessment of Conformal Additive Manufacturing Using Image Reconstruction. Paper presented at the International Design Engineering Technical Conferences and Computers and Information in Engineering Conference.

43. Lee, K., \& Jee, H. (2015). Slicing algorithms for multi-axis 3-D metal printing of overhangs. Journal of Mechanical Science and Technology, 29(12), 5139-5144.

44. Li, L., Haghighi, A., \& Yang, Y. (2018). A novel 6-axis hybrid additive-subtractive manufacturing process: Design and case studies. Journal of Manufacturing Processes, 33, 150-160. doi:https://doi.org/10.1016/j.jmapro.2018.05.008 
45. Li, N., Li, Y., \& Liu, S. (2016). Rapid prototyping of continuous carbon fiber reinforced polylactic acid composites by 3D printing. Journal of materials processing technology, 238, 218-225. doi:https://doi.org/10.1016/j.jmatprotec.2016.07.025

46. Liu, Z., Wang, Y., Wu, B., Cui, C., Guo, Y., \& Yan, C. (2019). A critical review of fused deposition modeling 3D printing technology in manufacturing polylactic acid parts. The International Journal of Advanced Manufacturing Technology, 102(9-12), 2877-2889.

47. Maidin, S., Muhamad, M., \& Pei, E. (2015). Feasibility study of ultrasonic frequency application on fdm to improve parts surface finish.

48. Manapat, J. Z., Chen, Q., Ye, P., \& Advincula, R. C. (2017). 3D printing of polymer nano-composites via stereolithography. Macromolecular Materials and Engineering, 302(9), 1600553.

49. Manapat, J. Z., Mangadlao, J. D., Tiu, B. D. B., Tritchler, G. C., \& Advincula, R. C. (2017). High-strength stereolithographic 3D printed nano-composites: graphene oxide metastability. ACS applied materials \& interfaces, 9(11), 10085-10093.

50. Mohan, N., Senthil, P., Vinodh, S., \& Jayanth, N. (2017). A review on composite materials and process parameters optimisation for the fused deposition modelling process. Virtual and Physical Prototyping, 12(1), 47-59.

51. Murphy, C. A., \& Collins, M. N. (2018). Microcrystalline cellulose reinforced polylactic acid biocomposite filaments for 3D printing. Polymer Composites, 39(4), 1311-1320. doi:10.1002/pc.24069

52. Ning, F., Cong, W., Wei, J., Wang, S., \& Zhang, M. (2015). Additive manufacturing of CFRP composites using fused deposition modeling: effects of carbon fiber content and length. Paper presented at the International manufacturing science and engineering conference.

53. Park, S. J., Lee, J. E., Park, J. H., Lee, N. K., Lyu, M.-Y., Park, K., . . Park, S.-H. (2018). Enhanced Solubility of the Support in an FDM-Based 3D Printed Structure Using Hydrogen Peroxide under Ultrasonication. Advances in Materials Science and Engineering, 2018, 3018761. doi:10.1155/2018/3018761

54. Prashantha, K., \& Roger, F. (2017). Multifunctional properties of 3D printed poly (lactic acid)/graphene nano-composites by fused deposition modeling. Journal of Macromolecular Science, Part A, 54(1), $24-29$.

55. Qattawi, A., \& Ablat, M. A. (2017). Design consideration for additive manufacturing: fused deposition modelling. Open Journal of Applied Sciences, 7(6), 291-318.

56. Qattawi, A., Alrawi, B., \& Guzman, A. (2017). Experimental optimization of fused deposition modelling processing parameters: a design-for-manufacturing approach. Procedia Manufacturing, 10, 791-803.

57. Rahim, T. N. A. T., Abdullah, A. M., \& Md Akil, H. (2019). Recent developments in fused deposition modeling-based 3D printing of polymers and their composites. Polymer Reviews, 59(4), 589-624.

58. Selmi, S., Habibi, M., Laperrière, L., \& Kelouwani, S. (2020). Characterisation of Natural Flax Fibers Honeycomb: Compression Damage Analysis Using Acoustic Emission. Journal of Natural Fibers, 1-10. doi:10.1080/15440478.2020.1789531

59. Sender, C., Dantras, E., Dantras-Laffont, L., Lacoste, M., Dandurand, J., Mauzac, M., . . Bernès, A. (2007). Dynamic mechanical properties of a biomimetic hydroxyapatite/polyamide 6, 9 nano-composite. Journal of Biomedical Materials Research Part B: Applied Biomaterials: An Official Journal of The Society for Biomaterials, The Japanese Society for Biomaterials, and The Australian Society for Biomaterials and the Korean Society for Biomaterials, 83(2), 628-635.

60. Sezer, H. K., \& Eren, O. (2019). FDM 3D printing of MWCNT re-inforced ABS nano-composite parts with enhanced mechanical and electrical properties. Journal of Manufacturing Processes, 37, 339-347. doi:https://doi.org/10.1016/j.jmapro.2018.12.004

61. Shembekar, A. V., Yoon, Y. J., Kanyuck, A., \& Gupta, S. K. (2018). Trajectory planning for conformal 3d printing using non-planar layers. Paper presented at the International Design Engineering Technical Conferences and Computers and Information in Engineering Conference.

62. Shembekar, A. V., Yoon, Y. J., Kanyuck, A., \& Gupta, S. K. (2019). Generating robot trajectories for conformal three-dimensional printing using non-planar layers. Journal of Computing and Information Science in Engineering, 19(3).

63. Shirazi, S. F. S., Gharehkhani, S., Mehrali, M., Yarmand, H., Metselaar, H. S. C., Adib Kadri, N., \& Osman, N. A. A. (2015). A review on powder-based additive manufacturing for tissue engineering: selective laser sintering and inkjet 3D printing. Science and technology of advanced materials, 16(3), 033502. doi:10.1088/1468-6996/16/3/033502

64. Shirazi, S. F. S., Gharehkhani, S., Mehrali, M., Yarmand, H., Metselaar, H. S. C., Kadri, N. A., \& Osman, N. A. A. (2015). A review on powder-based additive manufacturing for tissue engineering: selective laser sintering and inkjet 3D printing. Science and technology of advanced materials.

65. Singh, B., Kumar, R., \& Singh Chohan, J. (2020). Polymer matrix composites in 3D printing: A state of art review. Materials Today: Proceedings. doi:https://doi.org/10.1016/j.matpr.2020.04.335

66. Spinelli, G., Kotsilkova, R., Ivanov, E., Petrova-Doycheva, I., Menseidov, D., Georgiev, V., . . Silvestre, C. (2020). Effects of Filament Extrusion, 3D Printing and Hot-Pressing on Electrical and Tensile Properties of Poly (Lactic) Acid Composites Filled with Carbon Nanotubes and Graphene. Nanomaterials, 10(1), 35.

67. Spinelli, G., Lamberti, P., Tucci, V., Kotsilkova, R., Ivanov, E., Menseidov, D., . . Adami, R. (2019). Nanocarbon/poly (lactic) acid for 3d printing: Effect of fillers content on electromagnetic and thermal properties. Materials, 12(15), 2369.

68. Tao, Y., Wang, H., Li, Z., Li, P., \& Shi, S. Q. (2017). Development and application of wood flour-filled polylactic acid composite filament for 3D printing. Materials, 10(4), 339.

69. Tian, X., Liu, T., Wang, Q., Dilmurat, A., Li, D., \& Ziegmann, G. (2017). Recycling and remanufacturing of 3D printed continuous carbon fiber reinforced PLA composites. Journal of Cleaner Production, 142, $1609-1618$. doi:https://doi.org/10.1016/j.jclepro.2016.11.139 
70. Tian, X., Liu, T., Yang, C., Wang, Q., \& Li, D. (2016). Interface and performance of 3D printed continuous carbon fiber reinforced PLA composites. Composites Part A: Applied Science and Manufacturing, 88, 198-205.

71. Urhal, P., Weightman, A., Diver, C., \& Bartolo, P. (2019). Robot assisted additive manufacturing: A review. Robotics and Computer-Integrated Manufacturing, 59, 335-345. doi:https://doi.org/10.1016/j.rcim.2019.05.005

72. Valerga, A. P., Batista, M., Salguero, J., \& Girot, F. (2018). Influence of PLA filament conditions on characteristics of FDM parts. Materials, 11(8), 1322.

73. Valino, A. D., Dizon, J. R. C., Espera, A. H., Chen, Q., Messman, J., \& Advincula, R. C. (2019). Advances in 3D printing of thermoplastic polymer composites and nano-composites. Progress in Polymer Science, 98, 101162. doi:https://doi.org/10.1016/j.progpolymsci.2019.101162

74. Vashishtha, V. K., Makade, R., \& Mehla, N. (2011). Advancement of rapid prototyping in aerospace industry-a review. International Journal of Engineering Science and Technology, 3(3), 2486-2493.

75. Wang, Z., Martin, N., Hini, D., Mills, B., \& Kim, K. (2017). Rapid fabrication of multilayer microfluidic devices using the liquid crystal display-based stereolithography 3D printing system. 3D Printing and Additive Manufacturing, 4(3), 156-164.

76. Wu, C., Dai, C., Fang, G., Liu, Y.-J., \& Wang, C. C. (2017). RoboFDM: A robotic system for support-free fabrication using FDM. Paper presented at the 2017 IEEE International Conference on Robotics and Automation (ICRA).

77. Wulle, F., Coupek, D., Schäffner, F., Verl, A., Oberhofer, F., \& Maier, T. (2017). Workpiece and machine design in additive manufacturing for multi-axis fused deposition modeling. Procedia CIRP, 60, 229-234.

78. Yang, L., Li, S., Li, Y., Yang, M., \& Yuan, Q. (2019). Experimental investigations for optimizing the extrusion parameters on FDM PLA printed parts. Journal of Materials Engineering and Performance, 28(1), 169-182.

79. Yao, T., Deng, Z., Zhang, K., \& Li, S. (2019). A method to predict the ultimate tensile strength of 3D printing polylactic acid (PLA) materials with different printing orientations. Composites Part B: Engineering, 163, $393-402$. doi:https://doi.org/10.1016/j.compositesb.2019.01.025

80. Yeong, W.-Y., Chua, C.-K., Leong, K.-F., \& Chandrasekaran, M. (2004). Rapid prototyping in tissue engineering: challenges and potential. TRENDS in Biotechnology, 22(12), 643-652.

81. Zareiyan, B., \& Khoshnevis, B. (2017). Interlayer adhesion and strength of structures in Contour Crafting-Effects of aggregate size, extrusion rate, and layer thickness. Automation in Construction, 81, 112-121.

82. Zhang, G. Q., Spaak, A., Martinez, C., Lasko, D. T., Zhang, B., \& Fuhlbrigge, T. A. (2016). Robotic additive manufacturing process simulation-towards design and analysis with building parameter in consideration. Paper presented at the 2016 IEEE International Conference on Automation Science and Engineering (CASE).

83. Zhao, G., Ma, G., Feng, J., \& Xiao, W. (2018). Non-planar slicing and path generation methods for robotic additive manufacturing. The International Journal of Advanced Manufacturing Technology, 96(9-12), 3149-3159.

84. Zhao, P., Rao, C., Gu, F., Sharmin, N., \& Fu, J. (2018). Close-looped recycling of polylactic acid used in 3D printing: An experimental investigation and life cycle assessment. Journal of Cleaner Production, 197, 1046-1055. doi:https://doi.org/10.1016/j.jclepro.2018.06.275

85. Zou, R., Xia, Y., Liu, S., Hu, P., Hou, W., Hu, Q., \& Shan, C. (2016). Isotropic and anisotropic elasticity and yielding of 3D printed material. Composites Part B: Engineering, 99, 506-513. doi:https://doi.org/10.1016/j.compositesb.2016.06.009 